\title{
The association between hemodynamic parameters and para clinical findings with mortality in heart failure
}

\begin{abstract}
The study subjects consisted of 120 patients who underwent right heart catheterization in our institution between March 2010 to April 2014. The results showed that there is a significant correlation between mortality and hemodynamic and paraclinical findings. With regards to the importance of heart failure as one of the most serious factors of mortality, finding the correlation between hemodynamic and paraclinical findings with mortality and morbidity of the patients can be helpful in application of therapeutic approaches. In the present study, we showed that there is a significant correlation between some hemodynamic and paraclinical findings with each other and with mortality that can be used as indices for mortality and morbidity of heart failure patients. But, more studies are needed for finding the correlation between hemodynamic and paraclinical patients with mortality and morbidity of heart failure patients.
\end{abstract}

Keywords: heart failure, mortality, morbidity, hemodynamic parameters, para clinical findings
Volume 4 Issue I - 2017

Parisa Ahmadi, Ahmad Amin
Iran University of Medical Sciences, Iran

Correspondence: Ahmad Amin, Department of heart failure, Rajaie Hospital, Niyayesh street, Tehran, Iran, Tel +98-2I22663292,Email amina33@gmail.com

Received: September 0I, 2016 | Published: February 21, 2017
Abbreviations: HF, heart failure; NYHA, new york heart association; BUN, blood urea nitrogen; HDL, high density lipoprotein; LDL, low density lipoprotein; VLDL, very low-density lipoprotein; ALT, alanine transaminase; AST, aspartate transaminase; ALK, alkaline phosphates; TG, triglyceride; CPK, creatine phosphokinase; $\mathrm{CKMB}$, creatine kinase-MB; FC, function class; $\mathrm{EF}$, ejection friction; LVEF, left ventricular ejection fraction; BNP, brain natriuretic peptid; $\mathrm{TSH}$, thyroid-stimulating hormone; SD, standard deviation; HR, heart rate; $\mathrm{BP}$, blood pressure; $\mathrm{S}$, systolic; $\mathrm{D}$, diastolic; CVP, central venous pressure; PAP, pulmonary artery pressure; S, systolic; D, diastolic; PWCP, pulmonary capillary wedge pressure; PVR, pulmonary vascular resistance; $\mathrm{SaO}_{2}$, arterial oxygen saturation; $\mathrm{PP}$, pulse pressure; HGB, hemoglobin, SVR, systemic vascular resistance; $\mathrm{RVP}$, right ventricular pressure; $\mathrm{CO}$, cardiac output; CI, cardiac index; HCT, hematocrit; MCHC, mean corpuscular hemoglobin concentration; $\mathrm{MCV}$, mean corpuscular volume; $\mathrm{MCH}$, mean corpuscular hemoglobin; RBC, red blood count; WBC, white blood count; PLT, platelet count; PT, prothrombin time; INR, international normalized ratio; PTT, partial thromboplastin time; ESR, erythrocyte sedimentation rate; TBILI, total bilirubin; DBILI, direct bilirubin; $\mathrm{TIBC}$, total iron binding capacity; $\mathrm{LDH}$, lactate dehydrogenase; $B S$, blood sugar; F, fasting; CRP, c-reactive protein

\section{Introduction}

Heart failure (HF) is a major public health problem, with a prevalence of more than 3500 cases per 100,000 people in Iran and more than 26 million worldwide. ${ }^{1,2} \mathrm{HF}$ is a disease with a bad prognosis and also its appearance commonly signals the final stage of numerous processes. Mortality is similar to that of the most frequent cancers, with $<50 \%$ 4-year survival., ${ }^{3,4}$ Despite this, present developments in therapy have brought enhanced quality of life and also survival to heart failure individuals. Nevertheless, improved survival and the numerous co morbidities ${ }^{5,6}$ are accompanied by further health conditions. Present research shows that substantial amount of heart failure patients die from procedures other than cardiac disease, in particular malignancies, respiratory problems and septicemias. ${ }^{7}$ Although current therapeutic approaches to heart failure have improved prognosis, mortality remains high even though, therefore in this study we evaluate the relation between measured indices in right heart catheterization and paraclinical findings with mortality and morbidity of heart failure patients.

\section{Materials and methods}

This cross-sectional study was conducted during 2010-2014. From patients with FC 2-4 EF $<30 \%$, NYHA, patients suffering from advanced heart failure and $\mathrm{LVEF}<30 \%$ were selected and para-clinical findings including hemoglobin, sodium, potassium, pro BNP, TSH, T4, T3 Cr, BUN, Uric acid, HDL, and LDL levels were measured in this patients and after calculating hemodynamic and measuring paraclinical findings with 1 month and then 2 months intervals, they were monitored for mortality rate and hospitalization and time to clinical worsening.

\section{Results and discussion}

\section{Results}

120 patients including 80 male (66.67\%) and 40 female (33.33\%) with mean age of $38.28 \pm 15.60$ and mean height of $172 \pm 10$ and mean weight of $70.85 \pm 16.19$ were included to evaluate the correlation between measured indices in catheterization of right heart and paraclinical findings with mortality and morbidity of patients with chronic heart failure. 18 patients $(14.9 \%)$ went under heart graft and 
15 patients $(12.4 \%)$ died. The interval between referring time and heart graft was $87.09 \pm 80.05$ days and the interval with the patient's mortality was $79.5 \pm 61.93$ days.

\section{Hemodynamic and paraclinical findings}

Hemodynamic and paraclinical findings of the patients are shown in Tables $1-4$.

Table I Hemodynamic parameters

\begin{tabular}{llll}
\hline Variable & Mean士S.D & Variable & \\
& & & $\begin{array}{l}\text { Mean } \pm \\
\text { S.D }\end{array}$ \\
& & & \\
$\begin{array}{l}\text { Heart Rate } \\
\text { (HR) }\end{array}$ & $86.98 \pm 15.29$ & $\begin{array}{l}\text { Systemic Vascular Resistance } \\
\text { (SVR) }\end{array}$ & $\begin{array}{l}19.29 \pm \\
7.52\end{array}$
\end{tabular}

\section{Systolic}

\section{Blood}

Pressure

$1 \mid 4.22 \pm 20.29$

Arterial Oxygen Saturation

$\left(\mathrm{SaO}_{2}\right)$

$93.17 \pm$

(BP)

\section{Diastolic \\ Blood \\ Pressure}

$7 \mid .8 I \pm 17.14$

Systolic Right Ventricular Pressure (RVP)

$60.09 \pm$ 22.97

(BP)

\section{Central \\ Venous \\ Pressure}

$14.34 \pm 7.19$

Diastolic Right Ventricular

$17.92 \pm$

(CVP)

Systolic

Pulmonary

Artery

Pressure

$52.25 \pm 28.85$

Pressure (RVP)

7.65

(PAP)

\section{Diastolic}

Pulmonary

Artery

$26.53 \pm 12.37$

Cardiac Index (Cl)

(PAP)

\section{Pulmonary}

Capillary

Wedge

Pressure

(PWCP)

$26.11 \pm 9.11$

AORTA-Sat

$90.40 \pm$

I I.5 |

Pulmonary

Vascular

Resistance

(PVR)
$36.00 \pm$

|3.4 |
Table 2 Complete blood count

\begin{tabular}{|c|c|}
\hline Variable & Mean士S.D \\
\hline Hemoglobin $(\mathrm{Hgb})(\mathrm{g} / \mathrm{dl})$ & $12.57 \pm 2.4$ \\
\hline Hematocrit (Hct) (\%) & $37.71 \pm 7.17$ \\
\hline $\begin{array}{l}\text { Mean Corpuscular Hemoglobin } \\
\text { Concentration }(\mathrm{MCHC})(\mathrm{g} / \mathrm{dl})\end{array}$ & $32.25 \pm 2.88$ \\
\hline Mean corpuscular volume (MCV) $(\mathrm{fl})$ & $76.16 \pm 21.43$ \\
\hline Mean Corpuscular Hemoglobin (MCH) (pg) & $27.78 \pm 3.87$ \\
\hline Red Blood Count (RBC) (Mil/ $\mu \mathrm{l})$ & $4.63 \pm 0.85$ \\
\hline White Blood Count (WBC) $(\mathrm{k} / \mu \mathrm{l})$ & $7.52 \pm 2.59$ \\
\hline Platelet count $(\mathrm{PLT})(\mathrm{k} / \mu \mathrm{l})$ & $204.86 \pm 80.10$ \\
\hline Prothrombin Time (PT) & $16.35 \pm 5.18$ \\
\hline International Normalized Ratio (INR) & $1.35 \pm 0.42$ \\
\hline Partial Thromboplastin Time (PTT) & $33.64 \pm 7.90$ \\
\hline Reticulocyte (\%) & $|| 4 \pm 0.4 \mid$. \\
\hline $\begin{array}{l}\text { Erythrocyte sedimentation rate (ESR) } \\
(\mathrm{mm} / \mathrm{h})\end{array}$ & $11.10 \pm 10.70$ \\
\hline
\end{tabular}

Hgb, hemoglobin; SVR, systemic vascular resistance; DRVP, diastolic right ventricular pressure; $\mathrm{CO}$, cardiac output; $\mathrm{Cl}$, cardiac index; Hct, hematocrit; $\mathrm{MCHC}$, mean corpuscular hemoglobin concentration; $\mathrm{MCV}$, mean corpuscular volume; $\mathrm{MCH}$, mean corpuscular hemoglobin; RBC, red blood count; WBC, white blood count; PLT, platelet count; PT, prothrombin time; INR, international normalized ratio; PTT, partial thromboplastin time; ESR, erythrocyte sedimentation rate

Table 3 Lipid profile, liver, kidney ad thyroid functional test

\begin{tabular}{|c|c|c|}
\hline Variable & & Mean士SD \\
\hline \multirow{5}{*}{ Lipid profile } & TG & $92.04 \pm 43.19$ \\
\hline & Cholesterol & \\
\hline & HDL & $41.42 \pm 24.93$ \\
\hline & LDL & $77.1 I \pm 21.63$ \\
\hline & VLDL & $|4.4| \pm 7.57$ \\
\hline \multirow{6}{*}{ Liver parameter } & ALT & $27.38 \pm 19.51$ \\
\hline & AST & $28.54 \pm 13.21$ \\
\hline & ALK & \\
\hline & TBILI & $1.57 \pm 1.03$ \\
\hline & DBILI & $0.56 \pm 0.54$ \\
\hline & ALT & $27.38 \pm \mid 9.51$ \\
\hline \multirow{5}{*}{ Thyroid parameter } & Free T3 & $2.95 \pm 0.64$ \\
\hline & Free T4 & $16.07 \pm 2.72$ \\
\hline & $\mathrm{T} 3$ & $1.16 \pm 0.60$ \\
\hline & $\mathrm{T} 4$ & $10.62 \pm 2.60$ \\
\hline & TSH & $3.87 \pm 5.58$ \\
\hline \multirow{4}{*}{ Kidney parameter } & BUN & $24.36 \pm 12.94$ \\
\hline & Creatinine & $1.01 \pm 0.29$ \\
\hline & Uric acid & $7.10 \pm 2.60$ \\
\hline & CPK & $67.74 \pm 44.59$ \\
\hline
\end{tabular}

TG,triglyceride; HDL, high-density lipoprotein; LDL, low-density lipoprotein; VLDL, Very low-density lipoprotein; ALT, alanine transaminase; AST, aspartate transaminase; ALK, alkaline phosphatase; TBILI, total bilirubin; DBILI, direct bilirubin; TSH, thyroid-stimulating hormone; BUN, blood urea nitrogen; CPK, creatine phosphokinase
HR, heart rate; BP, blood pressure; (S, systolic; D, diastolic); CVP, central venous pressure; PAP, diastolic pulmonary artery pressure; (S, systolic; D, diastolic); PWCP, pulmonary capillary wedge pressure; PVR, pulmonary vascular resistance; $\mathrm{SaO}_{2}$, arterial oxygen saturation; $\mathrm{PP}$, pulse pressure

Citation: Ahmadi P,Amin A.The association between hemodynamic parameters and para clinical findings with mortality in heart failure.J Lung Pulm Respir Res. 2017;4(I):I4-19.DOI: 10.15406/jlprr.2017.04.00II4 
Table 4 Electrolyte, Iron, PH status and other serum test

\begin{tabular}{llll}
\hline Variable & Mean \pm SD & Variable & Mean \pm SD \\
\hline Ca & $9.04 \pm 1.02$ & Pco2 & $39.28 \pm 7.18$ \\
$\mathrm{P}$ & $3.98 \pm 0.74$ & HCo3 & $26.57 \pm 5.69$ \\
$\mathrm{Na}$ & $3.99 \pm 0.74$ & CKMB & $17.33 \pm 5.16$ \\
$\mathrm{~K}$ & $4.14 \pm 0.47$ & LDH & $1400 \pm 540$ \\
Serum iron & $66.00 \pm 43.61$ & FBS & $98.17 \pm 32.79$ \\
Ferritin & $179.88 \pm 21.25$ & BS & $141.14 \pm 76.70$ \\
Mg & $2.13 \pm 0.62$ & Albumin & $45.04 \pm 21.21$ \\
TIBC & $309.38 \pm 112.80$ & CRP & $13.50 \pm 19.44$ \\
PH & $7.39 \pm 0.02$ & Pro-BNP & $6938 \pm 6236$
\end{tabular}

TIBC, total iron binding capacity; CKMB, creatine kinase-MB; LDH, lactate dehydrogenase; $B S$, blood sugar; $F$, fasting; CRP, $C$ - reactive protein; BNP, brain natriuretic peptid

\section{The correlation between hemodynamic parameters and paraclinical findings}

The results showed that there is a significant correlation between $\mathrm{HR}$ and paraclinical indices including $\mathrm{Ca}, \mathrm{PH}, \mathrm{CKMB}, \mathrm{ALT}, \mathrm{T} 4$, and ESR, also, there is a significant correlation between hemodynamic findings (such as CO ، CI ، SBP and...) and some paraclinical findings (Table 5).

\section{The correlation between laboratory findings with heart transplantation}

The results showed that there is a direct correlation between heart graft and hemodynamic and paraclinical findings including CKMB, PP, Aorta Sat, TSH, FT4, FT3 and BS and also there was no significant correlation between heart graft and other evaluating findings.

\section{Correlation between hemodynamic findings and paraclinical findings with morbidity}

During this study, the correlation of hemodynamic and paraclinical findings with mortality was evaluated. 39 patients (32.5\%) were available from 120 patients. The results showed that the most frequent referring after 1 month was for 19 patients and the least referring after 12 months was 1 case. Also, there was a significant correlation between mortality and some hemodynamic and paraclinical findings (Table 6).

Table $\mathbf{5}$ The correlation between hemodynamic parameters and paraclinical findings

\begin{tabular}{|c|c|}
\hline $\begin{array}{l}\text { Hemodynamic } \\
\text { Parameters }\end{array}$ & Paraclinical Parameters \\
\hline$(\mathrm{HR})$ & $\begin{array}{l}\mathrm{Ca}(r: 0.396, P=0.007), \mathrm{PH}(r:, \mathrm{CKMB}(r: 0.976, \mathrm{P}=0.00 \mathrm{I}), \mathrm{ALT}(r: 0.423, \mathrm{P}=0.00 \mathrm{I}), \mathrm{T} 4(r:-369, \mathrm{P}=0.04 \mathrm{I}), \mathrm{ESR}(r:-0.4 \mathrm{I} 0, \\
\mathrm{P}=0.002)\end{array}$ \\
\hline$(\mathrm{CO})$ & $\begin{array}{l}\text { Ferritin }(r: 0.6 I I, P=0.002), \text { TBILI }(r:-0.423, P=0.00 I), H b(r:-0.236, P=0.13), \text { Hct }(r:-0.30 I, P=0.003), R B C(r:-0.354 \text {, } \\
P=0.00), W B C(r:-0.294, P=0.002), I N R(r:-0.30 I, P=0.003), P T T(r:-0.264, P=0.0 I 0), B U N(r:-0.243, P=0.0 I I), C r(r:- \\
0.205, P=0.33), \text { Uric acid }(r:-0.39 I, P=0.000), \mathrm{Hco}_{3}(r:-0.577, P=0.049)\end{array}$ \\
\hline$(\mathrm{Cl})$ & $\begin{array}{l}\text { Ferritin }(r: 0.6 I I, P=0.002), \text { TBILI }(r:-0.423, P=0.00 I), H b(r:-0.236, P=0.13), \text { Hct }(r:-0.30 I, P=0.003), R B C(r:-0.354 \text {, } \\
P=0.00), W B C(r:-0.294, P=0.002), I N R(r:-0.30 I, P=0.003), P T T(r:-0.264, P=0.0 I 0), B U N(r:-0.243, P=0.0 I I), C r(r:- \\
0.205, P=0.33), \text { Uric acid }(r:-0.39 I, P=0.000), H \operatorname{co3}(r:-0.577, P=0.049)\end{array}$ \\
\hline$(\mathrm{SBP})$ & Uric $\operatorname{acid}(r:-0.240, P=0.029), T 3(r: 0.342, P=0.019), P(r:-0.266, P=0.042)$ \\
\hline (DBP) & $\mathrm{Na}(r: 0.293, \mathrm{P}=0.003), \mathrm{BUN}(r: 0.223, \mathrm{P}=0.029), \mathrm{TSH}(\mathrm{r}:-0.422, \mathrm{P}=0.005), \mathrm{MCHC}(\mathrm{r}:-0.2 \mid 4, \mathrm{P}=0.036)$ \\
\hline$(\mathrm{CVP})$ & $\begin{array}{l}\text { CKMB (r: 0.977, } P=0.004), F B S(r:-0243, P=0.03 I), B S(r:-0.844, P=0.00 I), B U N(r: 0.255, P=0.029), T G(r:-0380, \\
P=0.003), V L D L(r:-0.424, P=0.00 I), A L K(r: 0.294, P=0.013), T B I L I(r: 0.276, P=0.45), \text { Uric acid, T3 }\end{array}$ \\
\hline (SPAP) & Ferritin ( $r:-0.476, P=0.022), \mathrm{Hb}(r: 0.239, \mathrm{P}=0.0 \mathrm{I} 3), \mathrm{Hct}(\mathrm{r}: 0.25 \mathrm{I}, \mathrm{P}=0.0 \mathrm{I} 3), \mathrm{RBC}(\mathrm{r}: 290, \mathrm{P}=0.003), \mathrm{PT}(\mathrm{r}: 0.205, \mathrm{P}=0.048)$ \\
\hline (DPAP) & $\begin{array}{l}\text { Ferritin( } r:-0.534, P=0.0 I I), \text { TBILI }(r: 0.285, P=0.035) \text {, Uric acid }(r: 0.255, P=0.022), \text { Hct }(r: 0.207, P=0.48), R B C(r: 0.230 \text {, } \\
P=0.023), W B C(r: 0.257, P=0.010), P T(r: 0.242, P=0.023) \text {, INR }(r: 0.248, P=0.020)\end{array}$ \\
\hline$(P \vee R)$ & T4 (r: $-0.477, \mathrm{P}=0.003), \mathrm{TSH}(\mathrm{r}: 0.345, \mathrm{P}=0.039)$ \\
\hline$(\mathrm{SVR})$ & $\mathrm{T} 4(\mathrm{r}:-0.5 \mathrm{I} 6, \mathrm{P}=0.0 \mathrm{I0}), \mathrm{TSH}(\mathrm{r}: 0.706, \mathrm{P}=0.00)$ \\
\hline (DRVP) & $\begin{array}{l}\mathrm{P}, \mathrm{Na}(\mathrm{r}: 0.376, \mathrm{P}=0.024) \text {, Serum Iron }(r: 0.832, \mathrm{P}=0.002), \mathrm{TIBC}(\mathrm{r}: 0.754, \mathrm{P}=0.03 \mathrm{I}), \mathrm{ALK}(\mathrm{r}: 0.504, \mathrm{P}=0.0 \mathrm{I} 4), \mathrm{TBILI}(\mathrm{r}: \\
0.528, \mathrm{P}=0.024), \mathrm{T} 3(\mathrm{r}:-0.423, \mathrm{P}=0.045), \mathrm{Hb}(\mathrm{r}:-036 \mathrm{I}, \mathrm{P}=0.024), \mathrm{RBC}(\mathrm{r}:-0.526, \mathrm{P}=0.00 \mathrm{I}), \mathrm{PLT}(\mathrm{r}: 0.4 \mathrm{I} 8, \mathrm{P}=0.0 \mathrm{I} 2)\end{array}$ \\
\hline (O2-sat) & $\mathrm{PH}(\mathrm{r}: 0.699, \mathrm{P}=0.0 \mathrm{II})$ \\
\hline
\end{tabular}

HR, heart rate; CO, cardiac output; $\mathrm{Cl}$, cardiac index; BP, blood pressure; S, systolic; D, diastolic; CVP, central venous pressure; PAP, diastolic pulmonary artery pressure; PVR, pulmonary vascular resistance; SVR, Systemic vascular resistance; DRVP, diastolic right ventricular pressure; $A$ LT, alanine transaminase; ESR, erythrocyte sedimentation rate; BUN, blood urea nitrogen; ALK, alkaline phosphatase; TG, triglyceride; CKMB, creatine kinase-MB; TSH, thyroid-stimulating hormone; Hb, hemoglobin; Hct, hematocrit; MCHC, mean corpuscular hemoglobin concentration; RBC, red blood count; WBC, white blood count; PLT, platelet count; PT, prothrombin time; INR, international normalized ratio; PTT, partial thromboplastin time; TBILI, total bilirubin; TIBC, total iron binding capacity; BS, blood sugar; $F$, fasting 
Table 6 Correlation between hemodynamic findings and paraclinical findings with morbidity

\begin{tabular}{|c|c|c|c|}
\hline Date & Hemodynamic Para Clinical Parameters & Date & $\begin{array}{l}\text { Hemodynamic Para Clinical } \\
\text { Parameters }\end{array}$ \\
\hline$\left.\right|^{\text {st }}$ month & PTT (r: 0.239, P=0.0। 8), HDL (r:-0.304, P=0.0I I) & $7^{\text {th }}$ month & - \\
\hline $2^{\text {nd }}$ month & $\begin{array}{l}\text { WBC ( } r:-0.240, P=0.01 \mathrm{I}), \mathrm{Hct}(\mathrm{r}:-0.206, P=0.037), C R P(r:-0.760 \text {, } \\
P=0.048), P(r: 0.308, P=0.016)\end{array}$ & $8^{\text {th }}$ month & HDL ( $\mathrm{r}:-0.339, \mathrm{P}=0.004)$ \\
\hline $3^{\text {rd }}$ month & CRP (r: $-0.760, P=0.048), P(r: 0.300, P=0.019)$ & $9^{\text {th }}$ month & - \\
\hline $4^{\text {th }}$ month & $\begin{array}{l}\text { SRVP }(r:-0.329, P=0.034), \text { ESR }(r:-0.277, P=0.014), P H(r: 0.588, \\
P=0.035)\end{array}$ & $10^{\text {th }}$ month & $\operatorname{BUN}(r:-0.3 \mid 5, P=0.00 I)$ \\
\hline $5^{\text {th }}$ month & Reticulocyte ( $r:-0.760, P=0.048), C R P(r:-0.91 I, P=0.004)$ & I I th month & - \\
\hline $6^{\text {th }}$ month & - & $12^{\text {th }}$ month & - \\
\hline
\end{tabular}

PTT, partial thromboplastin time; HDL, high-density lipoprotein;WBC, white blood count; Hct, hematocrit; CRP, c- reactive protein; SRVP, systolic right ventricular pressure; ESR, erythrocyte sedimentation rate

\section{Correlation between hemodynamic and paraclinical findings with mortality}

The results showed that there is a significant correlation between mortality and hemodynamic and paraclinical findings include CKMB, $\mathrm{PP}$, Aorta Sat, CRP, $\mathrm{HCO}_{3}, \mathrm{Pco}_{2}, \mathrm{PH}$ and TIBC.

\section{Discussion}

In the present study, 120 patients including 80 men (66.67\%) and 40 women $(33.33 \%)$ with mean age of $38.28 \pm 15.60$ and mean height of $172 \pm 10$ and mean weight of $70.85 \pm 16.19$ were included to evaluate the correlation between measured indices in catheterization of right heart and paraclinical findings with mortality and morbidity of patients with chronic heart failure. 18 patients $(14.9 \%)$ went under heart graft and 15 patients $(12.4 \%)$ died. The interval between referring time and heart graft was $87.09 \pm 80.05$ days and the interval with the patient's mortality was $79.5 \pm 61.93$ days. This study was consistent with Ding et al. ${ }^{8}$ for gender, ${ }^{8}$ but was not parallel with Sakatani et al. ${ }^{8}$ in which the ratio of men to women was $1: 1{ }^{9}$ In our study, there was no significant correlation between mortality and gender that was consistent with results of Sakatani et al. ${ }^{8}$

Various studies have evaluated the relationship between hemodynamic indices and paraclinical findings and their correlation with mortality of the patients. In the present study, there was a significant correlation between tests relating to thyroid function including T3, T4 and TSH with some hemodynamic indices. The results showed that there is a significant correlation between $\mathrm{T} 3$ with SBP, CVP and DRVP and also between T4 and TSH with PVR and SVR and also TSH with DBP (Table 4). On the other hand, there was a significant correlation between graft surgery with serum levels of FT4, FT3 and TSH. Asvold et al. ${ }^{10}$ indicated that there is a linear significant relationship between TSH with $\mathrm{DBP}$ and $\mathrm{SBP}^{10}$ that these findings were consistent with ours. On the other hand, Danzi et al. ${ }^{10}$ findings and Volzke et al. ${ }^{10}$ findings did not show any correlation between thyroid hormones and hypertension that were not parallel with our results. ${ }^{11,12}$ Previous studies have shown that there is a correlation between serum levels of thyroid hormones with incidence of cardiovascular diseases, their prognosis and mortality of the patients. ${ }^{11,13}$ Thyroid hormones lead to elevation of basal metabolic rate in most tissues that causes alteration in cardiac output and hemodynamic indices. ${ }^{14-16}$
Studies have shown that there is a relationship between lipid profile and mortality of heart failure patients and treatment of the patients with lipid lowering therapy decreases mortality and improves the patient's status. In our study, there was a significant correlation between serum levels of TG and VLDL with hemodynamic index of CVP, but there was no significant relationship between TC, LDL, HDL, TG and VLDL with mortality rate of the patients. These results were inconsistent with Ding et al. ${ }^{8}$ results and results of Sakatani et al. ${ }^{8}$ study, which showed significant correlation between TC, LDL, HDL and TG with mortality rate of the patients. ${ }^{8,9}$

Studies have shown that there was a relationship between liver and kidney function with mortality rate of heart failure patients, and these disorders effect each other. ${ }^{17-20}$ In the present study, the relation between liver and kidney function tests with hemodynamic indices and mortality rate of the patients was evaluated. The results showed that there is a significant correlation between liver and kidney function tests with some hemodynamic indices, but there is no significant relationship between these tests with mortality rate of the patients. Kawabe et al. ${ }^{20}$ showed that there is a relationship between BUN levels and mortality rate ${ }^{21}$ also, Kearney et al. ${ }^{21}$ showed that there is a direct correlation between high serum creatinine and mortality in heart failure patients. ${ }^{22}$ These findings were not parallel with our results that might be due to the size of selected sample and severity of liver and kidney lesions.

The results of our study showed that there is a significant correlation between $\mathrm{CBC}$ and some hemodynamic indices (Table 1). Although there was no significant relationship between $\mathrm{CBC}$ and mortality of the patients, various studies showed that blood hemoglobin levels of patients and heart failure with their mortality. ${ }^{23}$ Varadarajan et al..$^{23}$ showed that low $\mathrm{Hb}$ levels $(<12 \mathrm{gm} / \mathrm{dl})$ is correlated with mortality of heart failure patient during 5years and indicated that low $\mathrm{Hb}$ levels $(<12 \mathrm{gm} / \mathrm{dl})$ can be used as an index in patient's mortality prediction. ${ }^{24}$ Although there was no significant correlation seen between $\mathrm{Hb}$ and mortality in our study, the reason might be due to normal level of $\mathrm{Hb}$ in the present study. Barron et al. ${ }^{24}$ evaluated 153,213 patients and showed that WBC count is correlated with advancement of acute myocardial infarction (AMI) and increase of patient's mortality in long time. ${ }^{25}$ Their results were inconsistent with our results which showed WBC count is not correlated with mortality that might be due to difference in sample volume and duration of patients following up. 
As shown in Table 3, there is a significant correlation between serum levels of $\mathrm{Ca}, \mathrm{P}, \mathrm{Na}, \mathrm{Fe}$, Ferrintin, TIBC, PH, CKMB, LDH, FBS, ALB and some hemodynamic indices. On the other hand, there was a correlation between heart graft in patients with CKMB, CRP, HCo3, $\mathrm{PCO} 2, \mathrm{PH}$ and TIBC. Also there was a significant correlation between mortality rate with CKMB and total protein. Aguilar et al. ${ }^{25}$ in their study on diabetic patients reported a significant relationship between HA1C and mortality, but mortality rate was decreased by control of the patient's glucose levels. ${ }^{26}$ The reason of difference between this study and our study can be due to having normal ranges of glucose levels among the patients. Landesberg et al. ${ }^{26}$ showed that there is a significant correlation between CKMB with mortality in heart failure patient's undergone surgery. ${ }^{27}$ These results were parallel with ours. $\mathrm{Hu}$ et al. ${ }^{27}$ showed that very high levels of LDH have a direct and significant correlation with mortality in heart failure patients, and this difference might be due to not very high levels of LDH in evaluated patients in this study, on the other hand, in $\mathrm{Hu}$ et al. ${ }^{27}$ there was a significant correlation between LDH with some hemodynamic indices such as PAP, CI, and PVR. ${ }^{28}$ Kamioka et al. ${ }^{28}$ showed that there is a correlation between mortality and CRP, and also, CRP can be used as an index for cardiac re-synchronization therapy. ${ }^{29}$ These findings were parallel with our findings which indicate that there is a significant correlation between heart graft and CRP, although they were not parallel in case of mortality.

In the present study, patients were evaluated in a one year interval study to determine the relationship between hemodynamic and para clinical findings with mortality. The results showed that the most frequent referring was after 1 month were 19 patients and the least referring after 12 months was a patient, also, no significant correlation was seen between mortality and some hemodynamic and paraclinical findings, but with regards to lacking of complete information about patients and their follow up, complete discussion is not effectual in this aspect.

\section{Conclusion}

With regards to the importance of heart failure as one of the most serious factors of mortality, finding the correlation between hemodynamic and paraclinical findings with mortality and morbidity of the patients can be helpful in application of therapeutic approaches. In the present study, we showed that there is a significant correlation between some hemodynamic and paraclinical findings with each other and with mortality that can be used as indices for mortality and morbidity of heart failure patients. Some limitations such as incomplete information of some patients and also short duration of following up, so more studies are needed for finding the correlation between hemodynamic and paraclinical patients with mortality and morbidity of heart failure patients.

\section{Acknowledgements}

None.

\section{Conflict of interest}

The author declares no conflict of interest.

\section{References}

1. Bahrami M, Etemadifar S, Shahriari M, et al. Caregiver burden among Iranian heart failure family caregivers: A descriptive, exploratory, qualitative study. Iran J Nurs Midwifery Res. 2014;19(1):56-63.
2. Ponikowski P, Anker SD, Al Habib KF, et al. Heart failure: preventing disease and death worldwide. ESC Heart Failure. 2014;1(1):4-25.

3. Goldberg RJ, Ciampa J, Lessard D, et al. Long-term survival after heart failure:a contemporary population-based perspective. Arch Intern Med. 2007;167(5):490-496.

4. Hobbs FD, Roalfe AK, Davis RC, et al. Prognosis of all-cause heart failure and borderline left ventricular systolic dysfunction:5 year mortality follow-up of the Echocardiographic Heart of England Screening Study (ECHOES). Eur Heart J. 2007;28(9):1128-1134.

5. Henkel DM, Redfield MM, Weston SA, et al. Death in heart failure a community perspective. Circ Heart Fail. 2008;1(2):91-97.

6. Mehta PA, Dubrey SW, McIntyre HF, et al. Mode of death in patients with newly diagnosed heart failure in the general population. Eur $J$ Heart Fail. 2008;10(11):1108-1116.

7. Seow SC, Chai P, Lee YP, et al. Heart failure mortality in Southeast Asian patients with left ventricular systolic dysfunction. J Card Fail. 2007; 13(6):476-481.

8. Ding D, Li X, Qiu J, et al. Serum lipids, apolipoproteins, and mortality among coronary artery disease patients. Biomed Res Int. 2014;2014:709756.

9. Sakatani T, Shirayama T, Suzaki Y, et al. The association between cholesterol and mortality in heart failure. Comparison between patients with and without coronary artery disease. Int Heart J. 2005;46(4):619 629.

10. Asvold BO, Bjøro T, Nilsen TI, et al. Association between blood pressure and serum thyroid-stimulating hormone concentration within the reference range:a population-based study. J Clin Endocrinol Metab. 2007;92(3):841-845.

11. Völzke H, Alte D, Dörr M, et al. The association between subclinical hyperthyroidism and blood pressure in a population-based study. $J$ Hypertens. 2006;24(10):1947-1953.

12. Danzi S, Klein I. Thyroid hormone and blood pressure regulation. Curr Hypertens Rep. 2003;5(6):513-520.

13. Westerink J, van der Graaf Y, Faber DR, et al. Relation between thyroid-stimulating hormone and the occurrence of cardiovascular events and mortality in patients with manifest vascular diseases. Eur $J$ Prev Cardiol. 2012;19(4):864-873.

14. Gomberg-Maitland M, Frishman WH. Thyroid hormone and cardiovascular disease. Am Heart J. 1998;135(2):187-196.

15. Coceani M, Iervasi G, Pingitore A, et al. Thyroid hormone and coronary artery disease: from clinical correlations to prognostic implications. Clin Cardiol. 2009;32(7):380-385.

16. Prisant LM, Gujral JS, Mulloy AL. Hyperthyroidism: a secondary cause of isolated systolic hypertension. J Clin Hypertens (Greenwich). 2006;8(8):596-599.

17. Klein I, Danzi S. Thyroid disease and the heart. Circulation. 2007;116(15):1725-1735.

18. Klein I, Ojamaa K. Thyroid hormone and the cardiovascular system. $N$ Engl J Med. 2001;344(7):501-509.

19. Allen LA, Felker GM, Pocock S, et al. Liver function abnormalities and outcome in patients with chronic heart failure: data from the Candesartan in Heart Failure: Assessment of Reduction in Mortality and Morbidity (CHARM) program. Eur J Heart Fail. 2009;11(2):170-177.

20. Lee SS, Liu H. Cardiovascular determinants of survival in cirrhosis. Gut. 2007;56(6):746-748. 
21. Kawabe M, Sato A, Hoshi T, et al. Impact of blood urea nitrogen for long-term risk stratification in patients with coronary artery disease undergoing percutaneous coronary intervention. IJC Heart \& Vessels. 2014;4:116-121.

22. Kearney MT, Fox KA, Lee AJ, et al. Predicting death due to progressive heart failure in patients with mild-to-moderate chronic heart failure. $J$ Am Coll Cardiol. 2002;40(10):1801-1808.

23. Groenveld HF, Januzzi JL, Damman K, et al. Anemia and mortality in heart failure patients: a systematic review and meta-analysis. $\mathrm{J} \mathrm{Am} \mathrm{Coll}$ Cardiol. 2008;52(10):818-827.

24. Varadarajan P, Gandhi S, Sharma S, et al. Prognostic significance of hemoglobin level in patients with congestive heart failure and normal ejection fraction. Clin Cardiol. 2006;29(10):444-449.

25. Barron HV, Harr SD, Radford MJ, et al. The association between white blood cell count and acute myocardial infarction mortality in patients $>$ 65 years of age:findings from the cooperative cardiovascular project. $J$ Am Coll Cardiol. 2001;38(6):1654-1661.
26. Aguilar D, Bozkurt B, Ramasubbu K, et al. Relationship of hemoglobin A1C and mortality in heart failure patients with diabetes. $\mathrm{J} \mathrm{Am}$ Coll Cardiol. 2009;54(5):422-428.

27. Landesberg G, Shatz V, Akopnik I, et al. Association of cardiac troponin, $\mathrm{CK}-\mathrm{MB}$, and postoperative myocardial ischemia with long-term survival after major vascular surgery. $\mathrm{J} \mathrm{Am} \mathrm{Coll} \mathrm{Cardiol.}$ 2003;42(9):1547-1554.

28. Hu EC, He JG, Liu ZH, et al. High levels of serum lactate dehydrogenase correlate with the severity and mortality of idiopathic pulmonary arterial hypertension. Exp Ther Med. 2015;9(6):2109-2113.

29. Kamioka M, Suzuki H, Yamada S, et al. High sensitivity C-reactive protein predicts nonresponders and cardiac deaths in severe heart failure patients after CRT implantation. Int Heart J. 2012;53(5):306-312. 